Original Research Article

\title{
Evaluation of rational drug use pattern using WHO prescribing indicators in a medical intensive care unit of a tertiary teaching hospital in Kerala, India
}

\author{
Shobha P.*, Messaline Sunitha
}

Department of Pharmacology, Sree Gokulam Medical College, Trivandrum, Kerala, India

Received: 04 May 2017 Accepted: 13 May 2017

*Correspondence to:

Dr. Shobha P.,

Email: sobhaent@gmail.com

Copyright: (C) the author(s), publisher and licensee Medip Academy. This is an openaccess article distributed under the terms of the Creative Commons Attribution NonCommercial License, which permits unrestricted noncommercial use, distribution, and reproduction in any medium, provided the original work is properly cited.

\begin{abstract}
Background: ICU patients are exposed to more number of life saving drugs and face drug related problems like therapeutic failure, drug interactions and frequent adverse drug reactions. The cost of ICU hospitalisation and money spent on medicines is also a huge burden on these patients. A study of prescribing pattern in an ICU set up will serve as a medical audit to monitor and evaluate the prescribing practices to make it more rational and cost effective.

Methods: A prospective observational study was carried out in a medical ICU of a tertiary care hospital. All the inpatients admitted in the medical ICU during the study period of 2 months were included in the study. The data obtained from the case sheets were used to assess the prescribing pattern and rationality of drug use.
\end{abstract}

Results: A total of 101 patients were admitted in 2 months. The most common illness for which the patients (22) were admitted was respiratory problems. Average number of drugs per prescription was 6.9. Cardiovascular system (23.9\%) drugs were the most frequently prescribed. Pantoprazole (77) was the single most commonly prescribed drug. $40 \%$ of the drugs were prescribed from the essential drug list. The average cost of medicines incurred per person in our study was 5126.33 in INR.

Conclusions: Polypharmacy and unwanted prescription of proton pump inhibitors can be avoided by prescribing more generics and drugs from essential drug list.

Keywords: Intensive care unit, Prescribing pattern, Polypharmacy, Rational drug use

\section{INTRODUCTION}

Drug utilization research is defined as "marketing, distribution, prescription and use of drugs in a society with special emphasis on resulting medical, social and economic consequences". It helps us to evaluate the pattern of drug use and early detection of irrational drug prescriptions. ${ }^{1}$ Patients admitted in medical intensive care unit (MICU) are usually seriously ill and suffer from severe chronic illnesses. Because of their critical condition, they are usually prescribed multiple drugs from various pharmacological class of drugs. ${ }^{2}$ Since these patients are exposed to more number of life saving drugs, they also face drug related problems like therapeutic failure, drug interactions and adverse drug reactions. ${ }^{3}$ The cost of ICU hospitalisation and money spent on medicines is also a huge burden in these patients. ${ }^{4}$

The study of prescribing pattern in an ICU serves as a medical audit to monitor and evaluate the prescribing practices to make it more rational and cost effective. ${ }^{5}$ Some studies done earlier on evaluation of prescription patterns reveals overprescribing, misuse of antimicrobials, use of unnecessary expensive drugs and injections. $^{6}$ Keeping these facts in mind, regular evaluation of drug use pattern will serve as tool in monitoring the changing prescribing factors and also will help the policy makers to make strict guidelines in future. 
The objective of this study is to assess the prescribing pattern and rationality of drug use in a medical ICU.

\section{METHODS}

A prospective observational study was conducted in the department of Medical ICU of Sree Gokulam Medical College in Trivandrum, Kerala. The study was conducted for the duration of two months of September and October 2016. Waiver to obtain informed consent was given by the institutional ethics committee.

All the inpatients admitted in the medical ICU during the study period were included in the study. Patient case sheets were obtained from ICU as well as from the medical records department to collect the relevant data. Necessary steps were taken not to divulge the patient information. Only inpatient number was noted down as patient identification and all data was stored and analysed in the department of Pharmacology.

To study the prescribing pattern the following data was collected age, gender, diagnosis at the time of discharge, comorbid conditions, duration of stay and the details of all the drugs prescribed for them [name (generic/brand), dose, formulation, route, frequency and cost]. To assess the rationality $\mathrm{WHO}$ core prescribing indicators were calculated, which includes:

- Average number of drugs per encounter

- Percentage of drugs prescribed by generic name

- Percentage of encounters with an antibiotic prescribed

- Percentage of encounters with an injection prescribed

- $\quad$ Percentage of drugs prescribed from essential drug list or formulary.

Data was entered in Microsoft excel and descriptive statistics was applied.

\section{RESULTS}

\section{Demographic data}

A total of 101 patients were admitted over 2 month duration. Maximum number of patients was in the age group of $61-80$ years $(47.5 \%)$ (Table 1$)$.

Table 1: Age categorisation ( $\mathrm{N}=101)$.

\begin{tabular}{|l|l|l|}
\hline Age in years & No. of patients & Percentage \\
\hline$<20$ & 3 & $3 \%$ \\
\hline $21-40$ & 16 & $15.8 \%$ \\
\hline $41-60$ & 22 & $21.8 \%$ \\
\hline $61-80$ & 48 & $47.5 \%$ \\
\hline$>80$ & 12 & $11.9 \%$ \\
\hline
\end{tabular}

Minimum age was 17 and maximum age was 95. The number of male patients (64) were more in number than females (37) (Figure 1).

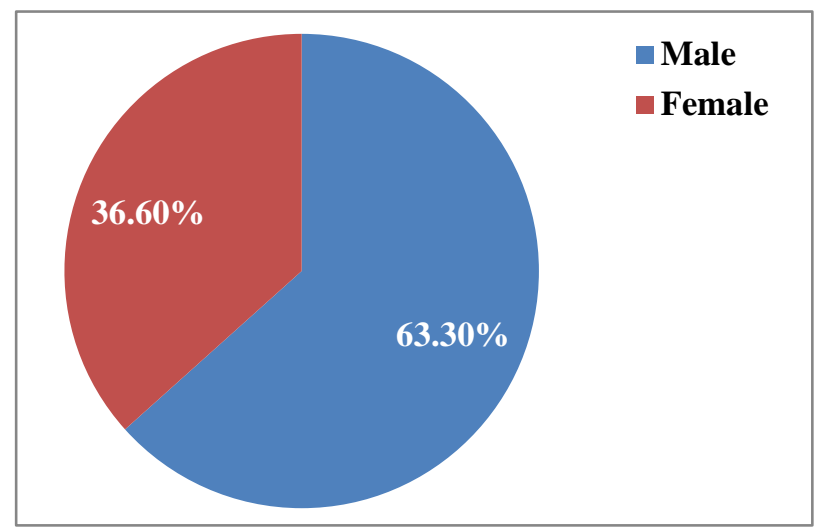

Figure 1: Gender categorization $(\mathrm{N}=101)$.

\section{Hospital stay, outcome and diagnosis}

The average number of days spent in the MICU was 6.7. Minimal stay was 1 day and maximum was 15 days. Most of the patients admitted were shifted to the ward $(46.5 \%)$ and others were discharged (36.6\%). Among the discharged patients, $(14.9 \%)$ were discharged at request against medical advice (Figure 2). The average cost of medications incurred per patient was 5126.33 in INR.

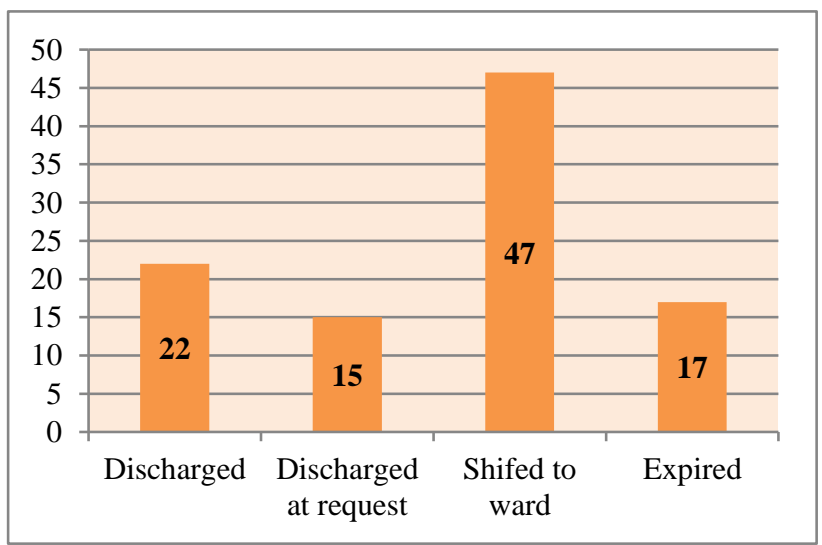

Figure 2: Patient outcome after admission.

The most common illness for which the patients (22) were admitted was respiratory problems followed by 21 patients with CNS related problems, 13 patients came with cardiovascular problems and another 13 with metabolic complications. (Table 2). Various co morbid concurrent illnesses were present in 60 patients. Type II diabetes mellitus was the commonest co morbid disease followed by hypertension.

\section{Prescription pattern}

Total number of drugs prescribed was 698. Average number of drugs per prescription is 6.9. The largest 
percentage of prescribed drugs belonged to cardiovascular system (23.9\%) followed by antimicrobials (17.9\%) (Figure 3). Pantoprazole (77) was the most commonly prescribed drug (Table 3). The other commonly prescribed were atorvastatin (30), low dose aspirin (23), paracetamol (22) and levetiracetam (21).

Table 2: Common illnesses diagnosed among admitted ICU patients.

\begin{tabular}{|ll|}
\hline System affected & Number (percentage) \\
\hline Respiratory system & $22(21.7 \%)$ \\
\hline Central nervous system & $21(20.7 \%)$ \\
\hline Cardiovascular system & $13(12.8 \%)$ \\
\hline Metabolic & $13(12.8 \%)$ \\
\hline GIT/liver & $6(5.9 \%)$ \\
\hline Fever & $15(14.8 \%)$ \\
\hline Kidney diseases & $5(4.9 \%)$ \\
\hline Poisoning & $3(2.9 \%)$ \\
\hline Others & $3(2.9 \%)$ \\
\hline
\end{tabular}

Poisoning includes snake bite/unknown bite/. Others include electrocution/ fall for observation

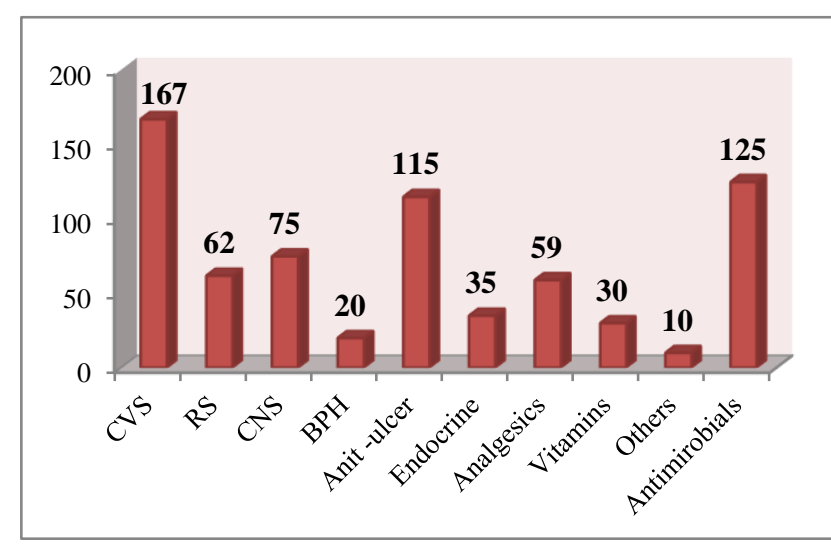

Others $=$ Antidotes/antisnake venom/ acetyl cysteine. BPH= benign prostatic hypertrophy

Figure 3: Common group of drugs prescribed.

Table 3: Commonly prescribed drugs.

\begin{tabular}{|ll|}
\hline Drugs & Number (Percentage) \\
\hline Pantoprazole & $77(11.03 \%)$ \\
\hline Atorvastatin & $30(4.29 \%)$ \\
\hline Low dose aspirin & $23(3.19 \%)$ \\
\hline Paracetamol & $22(3.15 \%)$ \\
\hline Levetiracetam & $21(3 \%)$ \\
\hline Ceftriaxone & $21(3 \%)$ \\
\hline
\end{tabular}

Total drugs no $=698$

\section{Analysis of WHO prescribing core indicators}

Prescribing core indicators were calculated according to WHO specifications (Table 4). The average number of drugs per prescription was 6.7. Total number of antibiotics prescribed was $125(17.9 \%)$. Around $38.5 \%$ of drugs were given as injections. $40 \%$ of the drugs were prescribed from the essential drug list. Percentage of drugs prescribed in generic name was $17.9 \%$.

\section{Table 4: WHO prescribing core indicators.}

\begin{tabular}{|ll|}
\hline Prescribing indicators & Values \\
\hline Average number of drugs per encounter & 6.9 \\
\hline $\begin{array}{l}\text { Percentage of drugs prescribed by generic } \\
\text { name }\end{array}$ & $\begin{array}{l}17.9 \% \\
(125)\end{array}$ \\
\hline $\begin{array}{l}\text { Percentage of encounters with an antibiotic } \\
\text { prescribed }\end{array}$ & $\begin{array}{l}37.2 \% \\
(260)\end{array}$ \\
\hline $\begin{array}{l}\text { Percentage of encounters with an injection } \\
\text { prescribed }\end{array}$ & $73 \%$ \\
\hline $\begin{array}{l}\text { Percentage of drugs prescribed from } \\
\text { essential drug list or formulary }\end{array}$ & $40 \%$ \\
\hline
\end{tabular}

\section{DISCUSSION}

Drug utilization studies conducted routinely provides current utilization and drug prescribing practices in the hospital. This helps in initiating and modifying rational prescribing practices and future policy making at national and local levels. ${ }^{1}$

Among 101 patinets, the no of males were more than females. This gender distribution was similar to another study done in Rajasthan. ${ }^{7}$ Maximum no of patients were in the age group of 61-80 years. This age distribution was different from the other parts in India. ${ }^{8,9}$ The average stay in ICU was 6.72 days which is on a higher side than the other studies. ${ }^{10}$ Longer the stay in the ICU, higher is the cost burden on the patient. The average cost per person in our study was 5126.33 in INR. Similar studies done in India have lesser average cost compared to our study, this high cost can be attributed to the no of days stayed in ICU which was also higher. ${ }^{10,11}$ Majority of the cost is due to the antibiotics prescribed, this pattern of prescribing costly, broad spectrum antibiotics was similar to other studies previously done in India. ${ }^{10}$ In an ICU set up broad spectrum antibiotics are prescribed empirically before the sensitivity results arrive. This will take 2 days, after which the antibiotics are changed based on the sensitivity reporting.

Around $14.9 \%$ patients were discharged against medical advice. The reason for this is unknown, further studies are required in the future to analyse the reason behind this to improve the patient compliance. The most common diagnosis for which the patient was admitted in the ICU was due to acute exacerbation of COPD. This disease pattern in Kerala is different from other states in India. This can be attributed as seasonal as the study was conducted in September and October which is rainy and cold in the southern state..$^{10,11}$

The average number of drugs per prescription in our study was 6.9. The reason for polypharmacy could be 
because of the emergency set up which may require empirical therapy before the final diagnosis is confirmed.

In total 698 drugs prescribed, drugs from cardiovascular system group were the commonly prescribed, among which lipid lowering drugs had the highest prescription. This pattern is due to the presence of concurrent co morbid conditions recorded in this study as hypertension and diabetes, for which atorvastatin was being frequently prescribed. Similar studies done in the past show that statins were prescribed more commonly in patients with diabetes and hypertension. ${ }^{12}$ In our study, the single most commonly prescribed drug was pantoprazole. This pattern was similar to studies done in other parts of India. ${ }^{10,13}$ The actual indication for pantoprazole prescription was not very clear. But various studies suggest that in an ICU set up, the incidence of stress ulcers and occult bleeding is very common. Hence prescription of anti ulcer drug is necessary. Hence many physicians prefer to prescribe proton pump inhibitors as a prophylactic measure for stress ulcers. Parenteral pantoprazole is costly and it will increase the total cost incurred and also add up to the number of injections taken by the patient. To reduce the cost for the patient, alternative drugs like $\mathrm{H} 2$ blockers can be prescribed or the patient can be shifted to oral proton pump inhibitors instead of intravenous preparations whenever possible which will be more cost effective. ${ }^{14}$

Analysing the WHO core indicators, the percentage of drugs prescribed in generic name was very less (17.9\%). Prescribing generic drugs will ensure the patients to get more affordable drugs and will also reduce the total cost burden on the patients. $40 \%$ of the drugs were only prescribed from the essential drug list. Prescribing more drugs from essential list will ensure rational prescription and also avoid unnecessary over prescription without appropriate indication.

\section{Limitations}

The main limitation of this study was the short duration of the study period and exclusion of surgery and neuro emergency care.

\section{CONCLUSION}

The study gives a baseline data of the prescribing practice in this emergency set up. Based on our study results we conclude that there was a high incidence of polypharmacy and unnecessary prescription of anti ulcer drugs. The study highlights the need for encouraging prescription of generic drugs and drugs from essential medicine list. An ICU protocol with an antibiotic policy can be initiated in this set up so that an initial prescription for different emergencies and infections can be done based on the hospital protocol which can be later changed after a clear diagnosis is made. This will ensure prescription of less costly drugs and avoid using parenteral proton pump inhibitors in all cases.

\section{ACKNOWLEDGMENTS}

Authors would like to acknowledge Dr. Bhasi, Professor of medicine and all the physicians in the ICU set up for their support and encouragement.

\section{Funding: No funding sources}

Conflict of interest: None declared

Ethical approval: The study was approved by the Institutional Ethics Committee

\section{REFERENCES}

1. World Health Organization. Introduction to drug utilization research. Geneva: WHO, 2003.

2. Townsend PL, Reynolds JR, Zaske DE. Applied Pharmacokinetics in the Intensive Care Unit. In: Irwin RS, Cerra FB, Rippe JM eds. Irwin and Rippe's Intensive Care Medicine, $4^{\text {th }}$ Ed. Philadelphia, Lippincott-Raven Publishers; 1999:1413.

3. Niederman MS. Appropriate use of antimicrobial agents: Challenges and strategies for improvement. Crit Care Med. 2003;31:608-16.

4. John LJ, Devi P, John J, Guido S. Drug utilization study of antimicrobial agents in medical intensive care unit of a tertiary care hospital. Asian J Pharm Clin Res. 2011;4(2):81-4.

5. Srishyla MV, Krishnamoorthy M, Naga Rani MA. Prescription audit in an Indian hospital setting using the DDD (defined daily dose) concept. Indian J Pharmacol. 1994;26:23-8.

6. Grand AL, Hogerzeil HV, Haaijer-Ruskamp FM. Intervention research in rational use of drugs: a review Health Policy and Planning. Oxford University Press. 1999;14(2):89-102.

7. Meena VK, Atray M, Agrawal A. Evaluation of Drug Utilization Pattern in Indoor Patients of Medicine Department at Tertiary Care Teaching Hospital in Southern Rajasthan. Int J Pharm Sci Res. 2016;7(9):3835-40.

8. Shankar PR, Partha P, Dubey AK, Mishra P, Deshpande VY. Intensive care unit drug utilization in a teaching hospital in Nepal. Kathmandu University Medical Journal. 2005;3(2):130-7.

9. Shelat PR, Gandhi AM, Patel PP. A Study of Drug Utilization Pattern According to Daily Define Dose in Intensive Care Unit at Tertiary Care Teaching Hospital, India. Journal of Young Pharmacists. 2015;7(4):349-58.

10. Kaur S, Rajagopalan S, Kaur N, Shafiq N, Bhalla A, Pandhi P, Malhotra S. Drug Utilization Study in Medical Emergency Unit of a Tertiary Care Hospital in North India. Emergency Medicine International. 2014:973578.

11. Barot PA, Malhotra SD, Rana DA, Patel VJ, Patel KP. Drug utilization in emergency medicine department at a tertiary care teaching hospital: A 
prospective study. J Basic Clin Pharma. 2013;4(4):78-81.

12. Raja S, Mohapatra S, Kumar J, Rani RJ. Prescription Patterns of Hypolipidaemic Drugs in a Tertiary Care Teaching Hospital of Southern India. JCDR. 2014;8(4):HC01-3.

13. Jacob J, Thomas C, Naaz A, Ramasamy R, Nazeem T, Shekar S. Study of Prescription Pattern in an Intensive Care Unit: A Prospective Observational Study. WJPPS. 2007;5(1):1125-32.
14. Daley RJ, Rebuck JA, Welage LS, Rogers FB. Prevention of stress ulceration: Current trends in critical care. Crit Care Med. 2004;32(10):2008-13.

Cite this article as: Shobha $\mathrm{P}$, Messaline $\mathrm{S}$.

Evaluation of rational drug use pattern using WHO prescribing indicators in a medical intensive care unit of a tertiary teaching hospital in Kerala, India. Int $\mathbf{J}$ Basic Clin Pharmacol 2017;6:1328-32. 